\title{
Mapping Malaria Transmission Risk in Northern Morocco Using Entomological and Environmental Data
}

\author{
E. Adlaoui, ${ }^{1}$ C. Faraj, ${ }^{1}$ M. El Bouhmi, ${ }^{2}$ A. El Aboudi, ${ }^{2}$ S. Ouahabi, ${ }^{1}$ A. Tran, ${ }^{3}$ \\ D. Fontenille, ${ }^{4}$ and R. El Aouad ${ }^{5}$
}

${ }^{1}$ Laboratoire d'Entomologie Médicale, Institut National d'Hygiène, 27 Avenue Ibn Batouta, Agdal, Rabat 10090, Morocco

${ }^{2}$ Faculté des Sciences, Université Mohamed V, Agdal, Rabat 10090, Morocco

${ }^{3}$ Agricultural Research Center for International Development (CIRAD), Epidemiology and Ecology of Animal Diseases, Montpellier Cedex 5, France

${ }^{4}$ Institut de Recherche pour le Développement (IRD), UR016, Caractérisation et Contrôle des Populations de Vecteurs, Montpellier Cedex 5, France

5 Institut National d'Hygiène, 27 Avenue Ibn Batouta, Agdal, Rabat 10090, Morocco

Correspondence should be addressed to E. Adlaoui, elbachirad@gmail.com

Received 18 July 2010; Revised 14 January 2011; Accepted 3 March 2011

Academic Editor: Virgílio E. do Rosário

Copyright ( $) 2011$ E. Adlaoui et al. This is an open access article distributed under the Creative Commons Attribution License, which permits unrestricted use, distribution, and reproduction in any medium, provided the original work is properly cited.

\begin{abstract}
Malaria resurgence risk in Morocco depends, among other factors, on environmental changes as well as the introduction of parasite carriers. The aim of this paper is to analyze the receptivity of the Loukkos area, large wetlands in Northern Morocco, to quantify and to map malaria transmission risk in this region using biological and environmental data. This risk was assessed on entomological risk basis and was mapped using environmental markers derived from satellite imagery. Maps showing spatial and temporal variations of entomological risk for Plasmodium vivax and P. falciparum were produced. Results showed this risk to be highly seasonal and much higher in rice fields than in swamps. This risk is lower for Afrotropical $P$. falciparum strains because of the low infectivity of Anopheles labranchiae, principal malaria vector in Morocco. However, it is very high for $P$. vivax mainly during summer corresponding to the rice cultivation period. Although the entomological risk is high in Loukkos region, malaria resurgence risk remains very low, because of the low vulnerability of the area.
\end{abstract}

\section{Background}

Until recently, malaria was endemic in Morocco. Three plasmodial species were present: Plasmodium falciparum, $P$. vivax, and P. malariae. Plasmodium falciparum was the dominant species until the beginning of the 1950s, when $P$. vivax became more important [1]. The most affected areas were those, which were most inundated, mainly the plains comprising swamps, which are the main breeding sites of the major vector in Morocco: Anopheles labranchiae.

Drainage and irrigation projects, undertaken at the beginning of the twentieth century have contributed to the reduction of malaria transmission, but disease was still common in the early 1960s. In 1965, a National Malaria Control Program was launched. It was based on vector control using DDT indoor residual spraying and parasite reservoir control by treatment and chemoprophylaxis. The effect on P. falciparum transmission was rapid, and the last autochthonous case was notified in 1973. Thirty years later, it was possible to interrupt $P$. vivax transmission. In 2008, Morocco undertook the process for certification of malariafree status according to WHO criteria.

However, Morocco still reports, every year, about one hundred of imported malaria cases. These are mainly detected in large urban areas, mainly Casablanca and Rabat, but also Fes and Agadir. Most of imported cases are $P$. falciparum originating from sub-Saharan Africa $[2,3]$.

Thus, malaria resurgence in Morocco remains a risk, because vectors are present in formerly malarious areas and because parasites are regularly imported. This risk may change with climatic and environmental modifications as well as increasing numbers of malaria parasite carriers coming from sub-Saharan Africa. 
The prevention of the reappearance of malaria transmission in Morocco relies on surveillance which should be based on a spatial and temporal stratification with respect to malariogenic risk factors, that is, vulnerability, receptivity, and infectivity [4]. The receptivity takes into account all parameters of the vectorial capacity of anopheline population (density, trophic behaviour, longevity, and duration of sporogonic cycle of Plasmodium). The infectivity (closely related to vectorial competence) is the ability of a particular parasite species to replicate in a given vector. Vulnerability corresponds to the risk of importing parasite carriers and of these becoming infective. National Malaria Control Program has a considerable inventory of entomological and parasitological information, and several areas of high risk are regularly studied and monitored $[5,6]$. Unfortunately, most of this information is only available in descriptive formats. Analysis of these data in association with environmental factors could reduce the need for very detailed field studies and allow generating maps of vector distribution and transmission risk. These would be useful for decision makers, by rapidly elucidating spatial patterns and permitting a better orientation and targeting of control measures.

In this study, we analyze the receptivity of the Loukkos area, one of the largest wetlands in Northern Morocco, to quantify and map malaria transmission risk in this region by integrating biological and environmental factors derived from high spatial resolution imagery.

\section{Methods}

2.1. Study Area. The study was carried out in the Loukkos area located in Northwestern Morocco on the Atlantic coast. It is situated between northwestern coordinate $35^{\circ} 09^{\prime} 47^{\prime \prime} \mathrm{N}, 06^{\circ} 09^{\prime} 16^{\prime \prime} \mathrm{E}$ and southeastern coordinate $34^{\circ} 56^{\prime} 55^{\prime \prime} \mathrm{N}, 05^{\circ} 59^{\prime} 58^{\prime \prime} \mathrm{E}$ (Figure 1). This region is characterized by a typically Mediterranean climate, with marked oceanic influences (low annual thermic amplitude and frequent dew). The total annual rainfall ranges from 600 and $800 \mathrm{~mm}$ concentrated mainly between October and April. The monthly mean low and high temperatures are ranging from 6 to $32^{\circ} \mathrm{C}$, respectively, during winter and summer. The landscape is composed of wetlands (coastal lagoons, swamps and rice fields), forests, and agricultural zones. Two study sites, in two different biotopes, were chosen to carry out this study. (1) Boucharen site located in an artificial wetland with controlled hydrology and characterized by the presence of large rice cultivation surfaces in continuous extension. The altitude is 1 to $15 \mathrm{~m}$ above sea level. (2) Beggara site located in a shallow swampy zone fed by river water and subject to the Atlantic Ocean tidal influence.

\subsection{Entomological Data}

2.2.1. Larval Sampling. Fifteen potential breeding sites, in each study area, located in the main biotopes potentially suitable to An. labranchiae larvae were visited every month from February to November 2008. Mosquito larvae, when present, were collected using plankton nets, counted and preserved in ethanol before being identified morphologically [7].

2.2.2. Sampling of Adult Mosquitoes. Adult mosquitoes were caught in the two sites, using three sampling techniques.

(i) Indoor resting mosquitoes were collected monthly from February to November in 4 stations (animal shelters) for two consecutive nights in each site. Mosquitoes were collected during 10 minutes per station using a sucking tube.

(ii) Human bait collection was conducted in two stations in each site. Landing catches were made, in each station, on two volunteers, one indoor and one outdoor from $08: 00 \mathrm{pm}$ to $05: 00 \mathrm{am}$ during two consecutive nights. These catches were made monthly from April to November in Boucharen and only in June and July in Beggara. Human biting rate was estimated as the average number of bites per person per night.

(iii) Five CDC light traps were deposited in each site during two consecutive nights in five different stations (animal shelters).

All collected adult mosquitoes were identified morphologically [7] and 3\% of adults of An. maculipennis complex was identified by multiplex polymerase chain reaction (PCR) [8].

All larvae and adults collection stations were georeferenced using a Global positioning system receiver (GPS).

2.2.3. Vectorial Capacity. Vectorial capacity (VC) was calculated using the formula of Garrett-Jones [9] derived from the works of MacDonald [10]:

$$
\mathrm{VC}=\frac{m a^{2} \cdot p^{n}}{-\ln p}
$$

where $m$ is vector-host ratio, that is, the anopheline density in relation to man, $a$ is vector biting rate, the average number of people bitten by one mosquito in one day, $p$ is daily survival rate, calculated as $p=\sqrt[u]{P}$ (where $P$ is the parous rate and $u$ is the trophogonic cycle duration in days), and $n$ is length in days of the sporogonic development.

The following parameters used in calculation of VC were estimated.

(i) Parity rate: was calculated during every session of capture according to the method of Detinova [11].

(ii) Human blood index: was measured by bloodmeal analysis of fed females using ELISA [12].

(iii) Trophogonic cycle: the duration of this cycle was calculated using the formula: $u=f_{1} /\left(T-g_{1}\right)$ where $f_{1}$ and $g_{1}$ are parameters depending on humidity and $T$ is the temperature [11]. $f_{1}$ and $g_{1}$ correspond respectively to $36.5^{\circ} \mathrm{C}$-days and $9.9^{\circ} \mathrm{C}$, for a relative humidity of $70-80 \%$ which characterizes the study region. 


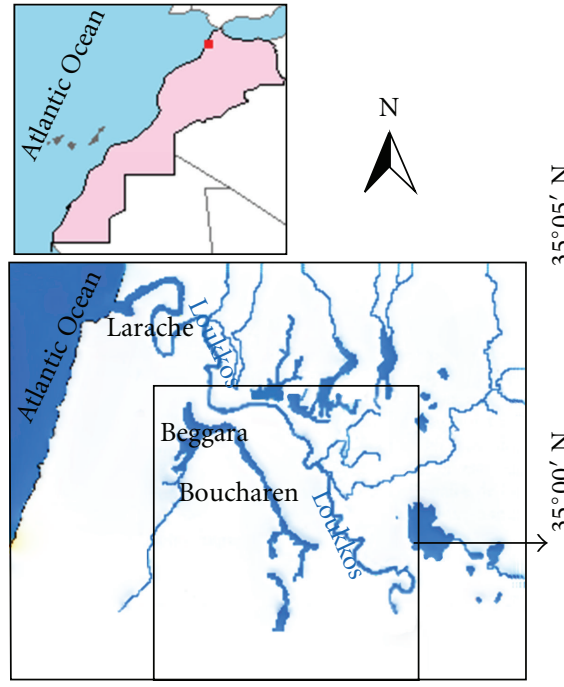

Rectangles represent study sites

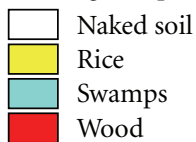

$06^{\circ} 05^{\prime} \mathrm{W}$

$06^{\circ} 00^{\prime} \mathrm{W}$

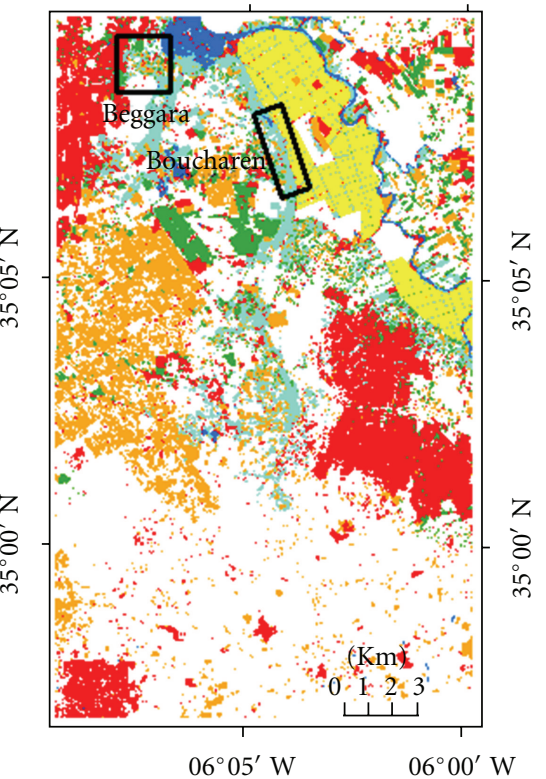

FIGURE 1: Maps showing location of study sites and land use in study area.

(iv) Sporogonic cycle: its duration was calculated as follows: $n=f_{2} /\left(T-g_{2}\right)$ where $f_{2}$ and $g_{2}$ are parameters depending on Plasmodium species [11] and are experimentally evaluated, respectively, at $111^{\circ} \mathrm{C}$-days and $16^{\circ} \mathrm{C}$ for $P$. falciparum and at the $105^{\circ} \mathrm{C}$-days and $14.5^{\circ} \mathrm{C}$ for $P$. vivax. Temperature above which the sporogony is impossible is estimated at $18^{\circ} \mathrm{C}$ and $16^{\circ} \mathrm{C}$ for $P$. falciparum and $P$. vivax, respectively [11].

(v) Infectivity: An. labranchiae infectivity to $P$. vivax and $P$. falciparum was estimated based on literature, respectively, to $0.5[1,13,14]$ and $0.05[15,16]$.

\subsection{Environmental Data}

2.3.1. Landscape Description. To identify and map the landscape units within the study area, a spot satellite image taken on July 22, 2007 was used. This image allows the study area $(14 \times 24 \mathrm{Km})$ to be covered in one scene with a spatial resolution of $10 \times 10$ meters. The classification of this image resulted in a land use map depicting the ecological units likely to impact Anopheles abundance (Figure 1).

2.3.2. Meteorological Data. Meteorological data recorded by the meteorological station of Loukkos were used. Mean monthly temperatures were used for the estimation of sporogonic and trophogonic cycle durations. Relative humidity average is considered in the calculation of the duration of the trophogonic cycle.

2.4. Risk Mapping Approach. To spatially characterize the risk, we used the approach developed by Tran et al. [17] based on a mosquito abundance regression logistic model which consists in using the results of the followup of larvae in different ecological units to identify specific larvae breeding sites (rice fields, different wetlands) and quantify the relationship between land cover, larvae presence, and adult abundance. Analysis of larval data led to the definition of a larval index that was defined as the probability of observing larvae in a point at least once during the mosquito season and was estimated by applying the logistic transformation to each pixel, within the image of the study area, according to its biotope. An adult abundance index was generated from the larval index and was also calculated for each pixel in the study area. This adult index was defined for each trap location as the mean value of the larval index within a buffer radius of $300 \mathrm{~m}$ around the trap location. This model showed a good overall accuracy (80\%) [17].

Hence, the model developed by Tran et al. [17] was applied to the land cover map of the Loukkos region. It resulted in a map of a larval index, corresponding to the probability of observing An. labranchiae larvae in a given breeding site. Then, an adult abundance index was produced from the larval index. Comparison of the adult abundance index and the number of indoor resting anophelines really 
captured in the same pixel showed a highly significant linear regression $\left(r^{2}=0.71, P<.01\right)$, allowing us to infer adult abundance index for each pixel in the Loukkos.

From this, the human biting rate (ma) was inferred from a comparison between mean of indoor resting anopheline catches and mean of human landing catches. Captures conducted the same night, in the same area and in pixels of the same adult abundance index class, were compared. Comparison showed a significant linear relationship between indoor resting anopheline and human landing catches $\left(r^{2}=\right.$ $0.61, P<.01)$. Subsequently, monthly predictive maps of human biting rate ( $\mathrm{ma}$ ) were produced.

Integration of the other vectorial capacity parameters (see Section 2.2.3), which are supposed to vary in time but not in space, as well as An. labranchiae susceptibility to Plasmodium species, $P$. falciparum, and P. vivax has allowed the spatiotemporal mapping of the entomological risk for each Plasmodium species.

\section{Results}

3.1. Collected Fauna. During this study, a total of 10168 adult anophelines among which 1239 in Beggara and 8928 in Boucharen were caught by the three collection methods. Catches by CDC light traps were very irregular with low production: only 405 mosquitoes were collected by this method while 7574 were cached on man and 2188 by indoor resting catches. Hence, catches by CDC light traps were not considered in this study.

The morphological identification of collected anophelines showed that they all belong to Maculipennis group. Molecular identification of 325 mosquitoes ( $3 \%$ of the total), collected in the two study sites by the three collection methods, showed that they all belong to An. labranchiae species. Results of indoor resting catches and human landing catches are presented in Table 1. Total density is higher in Boucharen, even development seems to begin earlier in Beggara. Peak densities are observed in May and June, respectively, in Beggara and Boucharen sites.

The larval investigations have permitted to collect 1137 larvae belonging all to An. labranchiae species and 861 Culicinae larvae belonging to Culex and Aedes genera.

Anopheles. labranchiae larvae were collected in the two study sites (Boucharen and Beggara) mostly in rice fields and swamps with, respectively, $80 \%$ and $56 \%$ of positive sites. About three quarters (73\%) of An. labranchiae larvae were collected in Boucharen. Collected larvae per type of larval habitats are represented in Table 2.

\subsection{Parameters Used in the Calculation of Vectorial Capacity.}

(i) The human blood index was measured on $354 \mathrm{fed}$ females: only eleven mosquitoes were engorged on man. The HBI was, then, estimated to 0.03 .

(ii) Parity rate: a total of 621 unfed females collected throughout the study period were dissected to estimate this parameter. It varies between 0.6 and 0.92 .

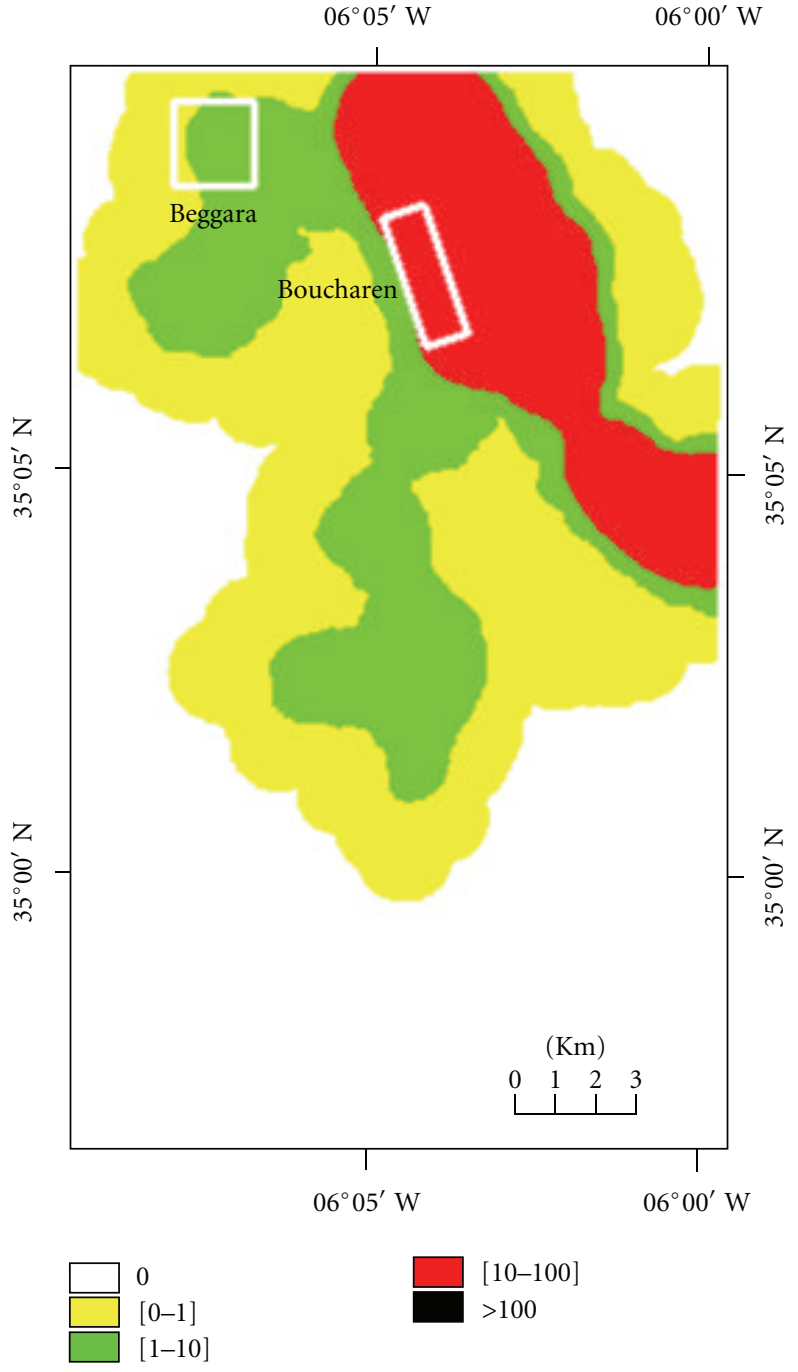

FIgURe 2: Spatial distribution of Plasmodium vivax transmission risk estimate in July in Loukkos. Classes were arbitrary chosen with a logarithmic scale.

Table 3 recapitulates the results of different parameters used in the calculation of the vectorial capacity during the study period in the two study sites. VC is higher in Boucharen than in Beggara for both Plasmodial species.

3.3. Entomological Risk. Entomological risk for P. vivax estimated during July and August are represented in Figures 2 and 3.

This risk is unimportant during the whole year for $P$. falciparum, presenting a maximum in August (Figure 4) while it is significant for $P$. vivax from May to October peaking in August.

\section{Discussion}

In the study area, An. labranchiae, the only representative of Maculipennis group in Morocco [5, 6, 18, 19], was the only anopheline species collected. Indeed, An. labranchiae finds its 
TABLE 1: Anopheles labranchiae in indoor resting catches and human landing catches, Loukkos 2008.

\begin{tabular}{|c|c|c|c|c|c|c|c|c|c|c|c|c|c|}
\hline Collection method & Locality & Coordinates & Feb. & March & April & May & June & July & August & Sept. & Oct. & Nov. & Total \\
\hline \multirow{10}{*}{ Indoor resting mosquitoes } & \multirow{4}{*}{ Boucharen } & $\begin{array}{l}35^{\circ} 07^{\prime} 49^{\prime \prime} \mathrm{N} \\
06^{\circ} 04^{\prime} 34^{\prime \prime} \mathrm{W}\end{array}$ & 6 & 14 & 22 & 86 & 131 & 52 & 70 & 23 & 21 & - & 425 \\
\hline & & $\begin{array}{l}35^{\circ} 07^{\prime} 40^{\prime \prime} \mathrm{N} \\
06^{\circ} 04^{\prime} 34^{\prime \prime} \mathrm{W}\end{array}$ & 4 & 17 & 15 & 82 & 75 & 53 & 34 & 19 & 70 & - & 369 \\
\hline & & $\begin{array}{l}35^{\circ} 07^{\prime} 37^{\prime \prime} \mathrm{N} \\
06^{\circ} 04^{\prime} 34^{\prime} \mathrm{W}\end{array}$ & 2 & 8 & 34 & 17 & 43 & 20 & 18 & 41 & 37 & - & 220 \\
\hline & & $\begin{array}{l}35^{\circ} 07^{\prime} 38^{\prime \prime} \mathrm{N} \\
06^{\circ} 04^{\prime} 34^{\prime \prime} \mathrm{W}\end{array}$ & 3 & 7 & 20 & 20 & 119 & 43 & 57 & 22 & 44 & - & 335 \\
\hline & \multirow{6}{*}{ Beggara } & Total & 15 & 46 & 91 & 205 & 368 & 168 & 179 & 105 & 172 & - & 1349 \\
\hline & & $\begin{array}{l}35^{\circ} 09^{\prime} 49^{\prime \prime} \mathrm{N} \\
06^{\circ} 06^{\prime} 56^{\prime \prime} \mathrm{W}\end{array}$ & 25 & 33 & 56 & 39 & 37 & 25 & 16 & 19 & 25 & 7 & 282 \\
\hline & & $\begin{array}{l}35^{\circ} 09^{\prime} 53^{\prime \prime} \mathrm{N} \\
06^{\circ} 06^{\prime} 51^{\prime \prime} \mathrm{W}\end{array}$ & 6 & 4 & 8 & 25 & 8 & 15 & 4 & 1 & 2 & 12 & 85 \\
\hline & & $\begin{array}{l}35^{\circ} 09^{\prime} 47^{\prime \prime} \mathrm{N} \\
06^{\circ} 06^{\prime} 57^{\prime \prime} \mathrm{W}\end{array}$ & 7 & 10 & 9 & 31 & 3 & 11 & 7 & 2 & 4 & 11 & 95 \\
\hline & & $\begin{array}{l}35^{\circ} 10^{\prime} 31^{\prime \prime} \mathrm{N} \\
06^{\circ} 06^{\prime} 47^{\prime \prime} \mathrm{W}\end{array}$ & 17 & 30 & 49 & 98 & 86 & 1 & 27 & 38 & 19 & 13 & 378 \\
\hline & & Total & 55 & 77 & 122 & 193 & 134 & 52 & 54 & 60 & 50 & 43 & 840 \\
\hline \multirow{6}{*}{ Human landing catches } & \multirow{3}{*}{ Boucharen } & $\begin{array}{l}35^{\circ} 07^{\prime} 09^{\prime \prime} \mathrm{N} \\
06^{\circ} 04^{\prime} 48^{\prime \prime} \mathrm{W}\end{array}$ & - & - & 7 & 65 & 634 & 861 & 1373 & 300 & 113 & - & 3353 \\
\hline & & $\begin{array}{l}35^{\circ} 07^{\prime} 55^{\prime \prime} \mathrm{N} \\
06^{\circ} 04^{\prime} 23^{\prime \prime} \mathrm{W}\end{array}$ & - & - & 11 & 82 & 694 & 1027 & 1565 & 372 & 121 & - & 3872 \\
\hline & & Total & - & - & 18 & 147 & 1328 & 1888 & 2938 & 672 & 234 & - & 7225 \\
\hline & \multirow{3}{*}{ Beggara } & $\begin{array}{l}35^{\circ} 09^{\prime} 53^{\prime \prime} \mathrm{N} \\
06^{\circ} 06^{\prime} 57^{\prime \prime} \mathrm{W}\end{array}$ & - & - & - & - & 62 & 94 & - & - & - & - & 156 \\
\hline & & $\begin{array}{l}35^{\circ} 09^{\prime} 45^{\prime \prime} \mathrm{N} \\
06^{\circ} 06^{\prime} 50^{\prime \prime} \mathrm{W}\end{array}$ & - & - & - & - & 79 & 114 & - & - & - & - & 193 \\
\hline & & Total & & & & & 141 & 208 & - & - & - & - & 349 \\
\hline
\end{tabular}

TABLE 2: Anopheles labranchiae larvae collected per larval habitat in study sites.

\begin{tabular}{|c|c|c|c|c|c|c|c|c|c|c|c|}
\hline & & Feb. & Mar. & April & May & June & July & Aug. & Sept. & Oct. & Nov. \\
\hline \multirow{4}{*}{ Boucharen } & Rice field & 0 & 0 & 0 & 87 & 171 & 157 & 119 & 92 & 69 & 2 \\
\hline & Swamp & 3 & 8 & 29 & 37 & 33 & 9 & 7 & 5 & 2 & 0 \\
\hline & Irrigated cultivation & 0 & 0 & 0 & 0 & 0 & 0 & 0 & 0 & 0 & 0 \\
\hline & Total & 3 & 8 & 29 & 124 & 204 & 166 & 126 & 97 & 71 & 2 \\
\hline \multirow{4}{*}{ Beggara } & Swamp & 9 & 46 & 86 & 79 & 59 & 11 & 8 & 5 & 4 & 0 \\
\hline & Irrigated cultivation & 0 & 0 & 0 & 0 & 0 & 0 & 0 & 0 & 0 & 0 \\
\hline & River & 0 & 0 & 0 & 0 & 0 & 0 & 0 & 0 & 0 & 0 \\
\hline & Total & 9 & 46 & 86 & 79 & 59 & 11 & 8 & 5 & 4 & 0 \\
\hline
\end{tabular}

preference area in the Atlantic plains in the Northwestern of the country where it constitutes more than $95 \%$ of the anopheline populations [20]. The study site, a large wetland situated in the plain of Loukkos, contains various types of larval habitats favourable to the development of mosquitoes particularly the swamps and rice fields, considered as preferred breeding sites of An. labranchiae. The proximity of human and animal (particularly bovine) agglomerations to the breeding sites makes this zone a very favourable biotope for the development of this species. In fact, the most dramatic malaria epidemics in the history of Morocco were registered in this area [1] when An. labranchiae was involved in the transmission of $P$. vivax, as well as of $P$. falciparum and $P$. malariae [21].

Larvae and adults of An. labranchiae were collected, all over the study period from February to November. These results corroborate those of Sicault et al. [22] as well as those of Guy and Holstein [23] who demonstrated that An. labranchiae has no spontaneous ovarian diapauses in Morocco; it may lay eggs even in winter in moderate 
TABLe 3: Vectorial capacity in the study sites, Loukkos 2008.

\begin{tabular}{|c|c|c|c|c|c|c|c|c|c|}
\hline & & April & May & June & July & August & Sept. & Oct. & Nov. \\
\hline Average temperature & & 15.71 & 18.31 & 21.36 & 23.58 & 23.48 & 22.00 & 20.37 & 16.58 \\
\hline Trophogonic duration in days $(u)$ & & 6.28 & 4.34 & 3.18 & 2.67 & 2.69 & 3.02 & 3.49 & 5.46 \\
\hline $\begin{array}{l}\text { Pf sporogonic cycle duration in } \\
\text { days }(n)\end{array}$ & & - & 48.05 & 20.71 & 14.64 & 14.84 & 18.50 & 25.40 & - \\
\hline $\begin{array}{l}\text { Pv sporogonic cycle duration in } \\
\text { days }(n)\end{array}$ & & - & 27.56 & 15.31 & 11.56 & 11.69 & 14.00 & 17.89 & 50.48 \\
\hline \multirow{4}{*}{ Boucharen } & Human biting rate (ma) & 2.25 & 18.38 & 166 & 236 & 367 & 84 & 57.25 & 1.25 \\
\hline & $\begin{array}{l}\text { Parity rate } \\
\text { (females dissected) }\end{array}$ & $\begin{array}{l}0.92 \\
(13)\end{array}$ & $\begin{array}{l}0.91 \\
(68)\end{array}$ & $\begin{array}{l}0.64 \\
(25)\end{array}$ & $\begin{array}{l}0.78 \\
(82)\end{array}$ & $\begin{array}{c}0.81 \\
(112)\end{array}$ & $\begin{array}{c}0.89 \\
(120)\end{array}$ & $\begin{array}{l}0.83 \\
(72)\end{array}$ & $\begin{array}{l}0.60 \\
(10)\end{array}$ \\
\hline & Pf. vectorial capacity & - & 2.06 & 0.61 & 7.29 & 16.32 & 10.58 & 3.23 & - \\
\hline & Pv. vectorial capacity & - & 3.21 & 1.31 & 9.71 & 20.89 & 12.59 & 4.59 & 0 \\
\hline \multirow{4}{*}{ Beggara } & Human biting rate (ma) & & & 32.25 & 52 & & & & \\
\hline & $\begin{array}{l}\text { Parity rate } \\
\text { (females dissected) }\end{array}$ & & & $\begin{array}{l}0.63 \\
(78)\end{array}$ & $\begin{array}{l}0.85 \\
(41)\end{array}$ & & & & \\
\hline & Pf. vectorial capacity & & & 0.10 & 3.93 & & & & \\
\hline & Pv. vectorial capacity & - & & 0.23 & 4.75 & & & & \\
\hline
\end{tabular}

Pf: Plasmodium falciparum.

Pv: Plasmodium vivax.

temperature. The increase of temperatures in resting shelters increases the activity of females after the winter [22, 24]. In this study, larval development began in February in the swampy zones (Beggara). The adults became abundant in the neighbouring villages from March. The rice fields (Boucharen area) became favourable to the development of larvae from their inundation in May, and larvae densities reached their maximum in June/July during the rice growing phase. In this period, wide areas of the swampy zones dried out or became unsuitable to the development of larvae because of their exploitation by man or standing about by cattle. Adult densities in the neighbouring villages are then appreciably lower. So, the complex swamp/rice field assures An. labranchiae development in the region of Loukkos all over the year.

Rice fields offer, by their biotic and abiotic characteristics, a much more favourable biotope to An. labranchiae larvae development in Morocco $[5,25,26]$. The results of this study confirm these earlier observations; in June, the receptivity of Boucharen village located near rice fields is 6 times higher than receptivity of Beggara situated near swamps.

Malaria transmission risk assessment or entomological risk is based on the evaluation of the vectorial capacity and vectorial competence of local vectors as defined by Garrett-Jones and Shidrawi [27]. The vectorial capacity is the best measure to quantify receptivity to malaria in a given region. Thus, the entomological risk corresponds to the product of the vectorial capacity and the infectivity (vectorial competence for a particular plasmodial species or strain). It is in the same area time, space and Plasmodium species dependant [28]. To study its variations in Loukkos, we characterized it spatially according to environmental markers generated from satellite images. Examination of the risk maps so produced shows that transmission risk varies strongly by environmental determinants which control the presence and extension of breeding sites and consequently the presence of vector and its density. This density is much higher around rice fields during the favourable transmission season. Indeed, rice fields are known for their role in maintaining a high entomological risk in the Mediterranean basin as this was demonstrated by several authors [5, 2931].

The risk variations in time are mainly influenced by climatic determinants, particularly the temperature which modulates the vectorial capacity of the vector populations by increasing their densities (by shortening their development cycle) and by decreasing the duration of trophogonic and sporogonic cycles.

Results obtained in this study clearly indicate that transmission risk is strongly higher for $P$. vivax than for $P$. falciparum in the various biotopes and during all the transmission period, which is extending from May to October. This is due to differences in the infectivity and the length of sporogonic cycle. Results of the current study suggest a possible transmission of $P$. falciparum, although low in Loukkos. The findings are at odds, with earlier reports of the apparent refractoriness of European An. labranchiae to tropical $P$. falciparum strains [32]. Such a different vectorial capacity between allopatric populations of the same species has been found in a number of other anopheline species. For example, An. stephensi mysorensis and An. fluviatilis T are known to act as vectors of malaria in Iran and Pakistan but seem not to be vectors in India [33-35].

Even though entomological risk is very high in Loukkos region, the malaria vulnerability (risk of presence of infective Plasmodium carriers) is very low. Although Morocco notifies every year about one hundred imported malaria cases, these are notified particularly in big cities where transmission conditions are absent. The probability that these carriers contact the vector in the potential transmission zones during 


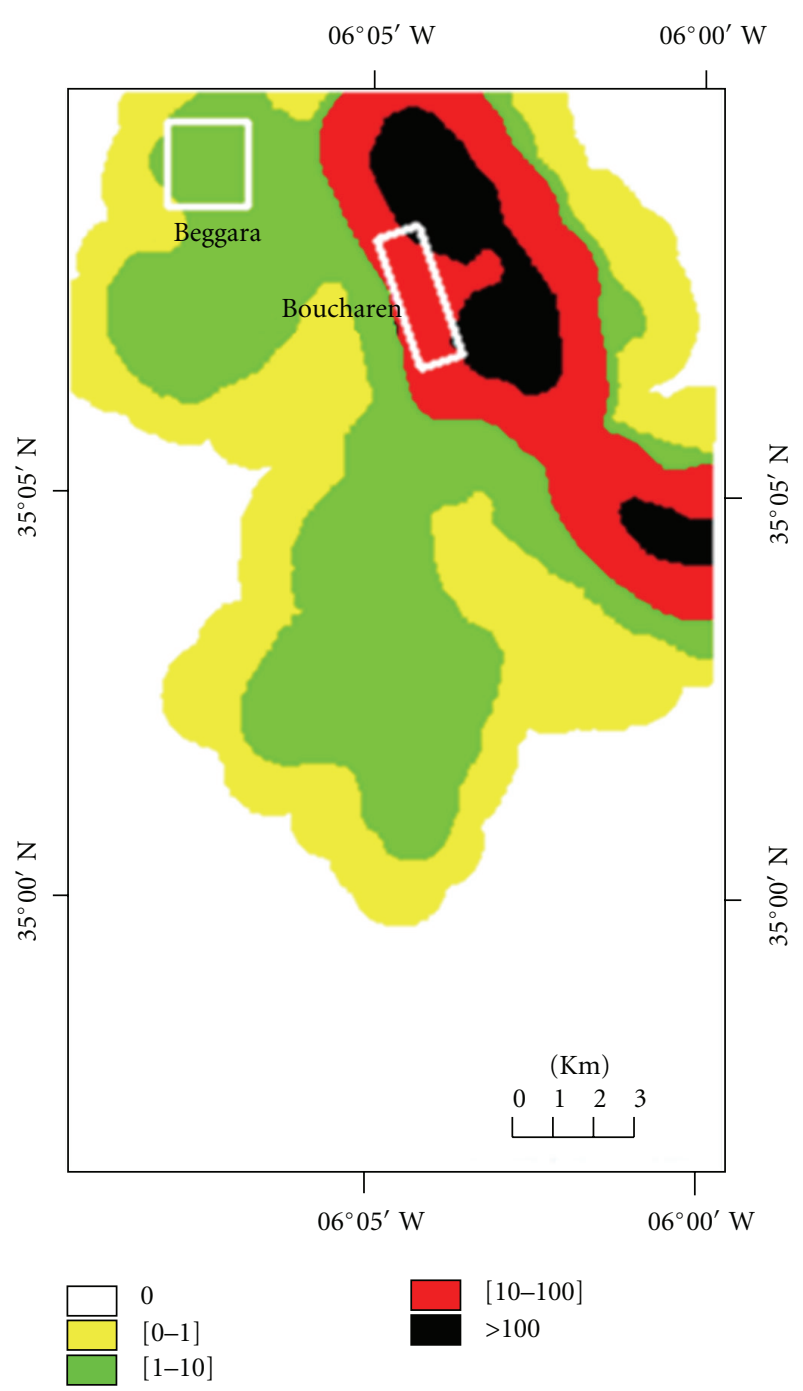

Figure 3: Spatial distribution of Plasmodium vivax transmission risk estimate in August in Loukkos. Classes were arbitrary chosen with a logarithmic scale.

the transmission season is very low. Since 1996, only 5 imported malaria cases were notified in Larache city, about $10 \mathrm{~km}$ from the study area (Ministry of Health, unpublished data).

The most worrying situation would result from the exposure of local vectors to imported $P$. vivax. Indeed the number of cases of $P$. vivax imported malaria is in net growth; it increased from $1.5 \%(1 / 69)$ in 2003 to $9 \%(13 / 142)$ in 2008 . These cases come particularly from Mauritania. It is therefore important to maintain strict surveillance, particularly for importation of $P$. vivax to areas with environmental characteristics similar to Loukkos.

In synthesis, the malaria resumption risk in Loukkos is low but growing. The increase of African populations arriving clandestinely from malaria endemic zones and the perpetual change of land cover factors can lead to increased malaria risk. Continuous contact with exotic strains of Plasmodium could in the long term lead to the selection

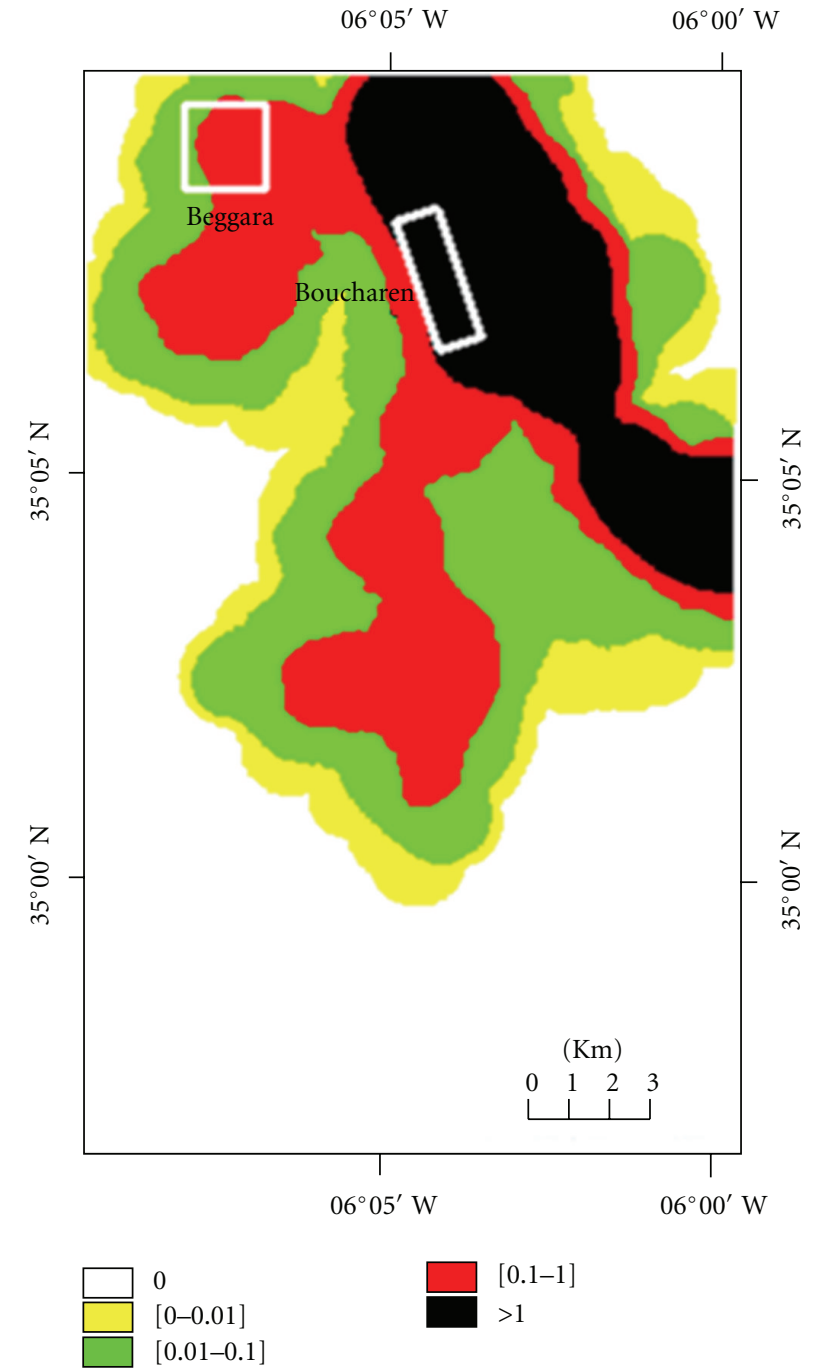

Figure 4: Spatial distribution of Plasmodium falciparum transmission risk estimate in August in Loukkos. Classes were arbitrary chosen with a logarithmic scale.

and/or to the adaptation of strains able to develop better in local vectors.

This indicates the need for focused, but flexible, epidemiological surveillance to prevent any possibility of encounters between potential vectors and gametocyte carriers. The present work can be considered as a public health tool designated to help manage malaria risk and to better use available resources by focusing actions to areas most at risk.

\section{Conflict of Interests}

The authors declare that they have no Conflict of interests.

\section{Acknowledgments}

The authors thank Dr Allan Shapira for his thoughtful review of the paper. The authors thank M. El Kohli, L. Laqraa, and M. El Rhazi for their precious technical 
collaboration on field and in laboratory. The authors also thank the staff of the medical delegation of Larache for their support and collaboration and N. Dessay (Institut de Recherche pour le Développement) and L. Guerrini (Centre de coopération Internationale en Recherche Agronomique pour le Développement) for their kind help in the risk mapping study. This work received the technical and financial support of the European grant GOCE-2003-010284 EDEN. The paper is catalogued by the EDEN Steering Committee as EDEN0229. The contents of this publication are the sole responsibility of the authors and can in no way be taken to reflect the views of the European Union. E. Adlaoui and C. Faraj contributed equally to this work.

\section{References}

[1] World Health Organization, Malaria in Morocco: Relentless Efforts towards the Goal of Elimination, WHO-EM/MAL/345/E 2007, World Health Organization, 2007.

[2] N. Soraa, M. K. Moudden, R. Moutaj, M. Zyani, A. Hda, and M. Jana, "Paludisme d'importation à l'hôpital militaire Avicenne de Marrakech: à propos de 68 cas en quatre ans," Médecine et Armées, vol. 34, no. 5, pp. 463-467, 2006.

[3] A. El Ouali Lalami, M. Cherigui, S. Ibnsouda Koraichi, S. Maniar, N. El Maimouni, and M. Rhajaoui, "Le paludisme importé dans le Centre Nord du Maroc entre 1997 à 2007," Cahiers Santé, vol. 19, no. 1, pp. 43-47, 2009.

[4] J. H. Pull, "Simple méthodologie pour estimer le potentiel paludogène d'une zone," Document Technique, Division du Paludisme à l'Organisation Mondiale de la Santé, 1979.

[5] C. Faraj, S. Ouahabi, E. Adlaoui, D. Boccolini, R. Romi, and R. El Aouad, "Risque de réémergence du paludisme au Maroc étude de la capacité vectorielle d'Anopheles labranchiae dans une zone rizicole au nord du pays," Parasite, vol. 15, no. 4, pp. 605-610, 2008.

[6] C. Faraj, E. Adlaoui, S. Ouahabi, M. Rhajaoui, D. Fontenille, and M. Lyagoubi, "Entomological investigations in the region of the last malaria focus in Morocco," Acta Tropica, vol. 109, no. 1, pp. 70-73, 2009.

[7] J. Brunhes, A. Rhaim, B. Geoffroy, G. Angel, and J. P. Hervy, Les Moustiques de l'Afrique Méditerranéenne. Logiciel d'Identification et d'Enseignement, IRD \& IPT, Montpellier, France, 2000, CDRom collection didactique.

[8] J. Proft, W. A. Maier, and H. Kampen, "Identification of six sibling species of the Anopheles maculipennis complex (Diptera: Culicidae) by a polymerase chain reaction assay," Parasitology Research, vol. 85, no. 10, pp. 837-843, 1999.

[9] C. Garrett-Jones, "The human blood index of malaria vectors in relation to epidemiological assessment," Bulletin of the World Health Organization, vol. 30, pp. 241-261, 1964.

[10] G. Macdonald, The Epidemiology and Control of Malaria, Oxford University Press, London, UK, 1957.

[11] T. S. Detinova, Age-Grouping Methods in Diptera of Medical Importance with Special Reference to Some Vectors of Malaria, Monograph Series, 47, World Health Organization, 1963.

[12] J. C. Beier, P. V. Perkins, R. A. Wirtz et al., "Bloodmeal identification by direct enzyme-linked immunosorbent assay (ELISA), tested on Anopheles (Diptera: Culicidae) in Kenya," Journal of Medical Entomology, vol. 25, no. 1, pp. 9-16, 1988.

[13] G. Houel, "Note sur l'orientation trophique de An. labranchiae au Maroc," Bulletin de l'Institut d'Hygiène du Maroc, vol. 15, no. 3, pp. 387-391, 1955.
[14] M. Holstein, "Problèmes de l'anophelisme au Maroc," Rapport OMS, 1966.

[15] C. Faraj, S. Ouahabi, E. Adlaoui, and R. El Aouad, "Etat actuel des connaissances sur les Anophèles du Maroc (Diptera: Culicidae): systématique, distribution géographique et compétence vectorielle," Revue d'Epidémiologie et de Santé Publique, vol. 58, no. 5, pp. 349-357, 2010.

[16] C. Toty, H. Barré, G. Le Goff et al., "Malaria risk in Corsica, former hot spot of malaria in France," Malaria Journal, vol. 9, no. 1 , article 231, 2010.

[17] A. Tran, N. Ponçon, C. Toty et al., "Using remote sensing to map larval and adult populations of Anopheles hyrcanus (Diptera: Culicidae) a potential malaria vector in Southern France," International Journal of Health Geographics, vol. 7, no. 9, 2008.

[18] C. Faraj, E. Adlaoui, N. Saaf et al., "Note sur le complexe Anopheles maculipennis au Maroc," Bulletin de la Société de Pathologie Exotique, vol. 97, no. 4, pp. 293-294, 2004.

[19] C. Faraj, E. Adlaoui, C. Brengues, D. Fontenille, and M. Lyagoubi, "Resistance d'An. labranchiae au DDT au Maroc: mise au point, identification des mécanismes et choix d'un insecticide de remplacement," Eastern Mediterranean Health Journal, vol. 14, no. 4, pp. 776-783, 2008.

[20] J. Gaud, F. Faure, and A. Maurice, "Répartition et fréquence relative des espèces anophéliennes au Maroc," Annales de Parasitologie Humaine et Comparée, vol. 25, pp. 53-60, 1950.

[21] G. Houel and F. Donadille, "Vingt ans de lutte antipaludique au Maroc," Bulletin de l'Institut d'Hygiène du Maroc, vol. 13, pp. 3-51, 1953.

[22] G. Sicault, A. Messerlin, J. Lumeau, and J. Fritz, "Le paludisme dans le Gharb," Bulletin de l'Institut d'Hygiène du Maroc, vol. 5, pp. 5-91, 1935.

[23] Y. Guy and M. Holstein, "Données récentes sur les Anophèles du Maghreb," Archives de l'Institut Pasteur d'Algerie, vol. 46, pp. 142-150, 1968.

[24] G. Metge, "Contribution à l'étude ècologique et biologique d'Anopheles labranchiae au Maroc: activitè des imagos, dynamique des stades pré-imaginaux dans la région de Sidi Bettache," Bulletin d'Ecologie, vol. 22, pp. 419-426, 1991.

[25] D. Houel, "La lute antipaludique dans les zones rizicoles du Maroc," Bulletin de l'Institut d'Hygiène du Maroc, vol. 14, pp. 43-90, 1954.

[26] J. Gaud, D. Mechali, and J. Delrieu, "Riziculture et paludisme au Maroc," Bulletin de l'Institut d'Hygiène du Maroc, vol. 9, pp. 181-190, 1949.

[27] C. Garrett-Jones and G. R. Shidrawi, "Malaria vectorial capacity of a population of Anopheles gambiae: an exercise in epidemiological entomology," Bulletin of the World Health Organization, vol. 40, no. 4, pp. 531-545, 1969.

[28] N. Ponçon, A. Tran, C. Toty, A. J. F. Luty, and D. Fontenille, "A quantitative risk assessment approach for mosquito-borne diseases: malaria re-emergence in southern France," Malaria Journal, vol. 7, article 147, 2008.

[29] R. Romi, G. Pierdominici, C. Severini et al., "Status of malaria vectors in Italy," Journal of Medical Entomology, vol. 34, no. 3, pp. 263-271, 1997.

[30] R. Romi, G. Sabatinelli, and G. Majori, "Could malaria reappear in Italy?" Emerging Infectious Diseases, vol. 7, no. 6, pp. 915-919, 2001.

[31] N. Ponçon, T. Balenghien, C. Toty et al., "Effects of local anthropogenic changes on potential malaria vector Anopheles hyrcanus and west Nile virus vector Culex modestus, Camargue, France," Emerging Infectious Diseases, vol. 13, no. 12, pp. 1810-1815, 2007. 
[32] J. De Zulueta, C. D. Ramsdale, and M. Coluzzi, "Receptivity to malaria in Europe," Bulletin of the World Health Organization, vol. 52, no. 1, pp. 109-111, 1975.

[33] M. A. Oshaghi, F. Yaaghoobi, and M. R. Abaie, "Pattern of mitochondrial DNA variation between and within Anopheles stephensi (Diptera: Culicidae) biological forms suggests extensive gene flow," Acta Tropica, vol. 99, no. 2-3, pp. 226-233, 2006.

[34] A. Mehravaran, M. A. Oshaghi, H. Vatandoost et al., "First report on Anopheles fluviatilis $U$ in southeastern Iran," Acta Tropica, vol. 117, no. 2, pp. 76-81, 2011.

[35] S. R. Naddaf, M. A. Oshaghi, H. Vatandoost, and M. Assmar, "Molecular characterization of Anopheles fluviatilis species complex in the Islamic Republic of Iran," Eastern Mediterranean Health Journal, vol. 9, no. 3, pp. 257-265, 2003. 


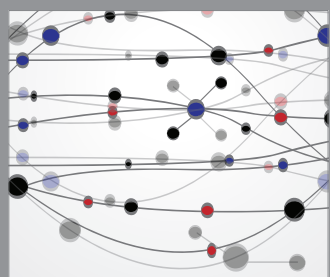

The Scientific World Journal
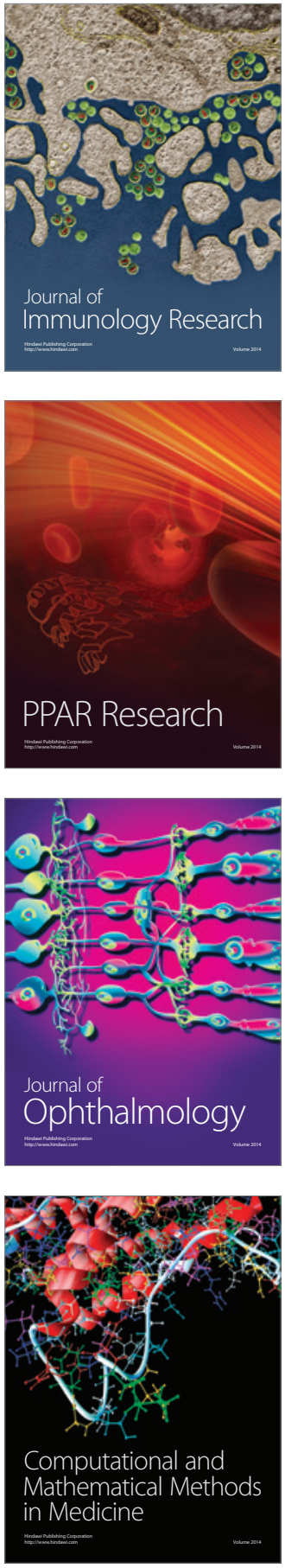

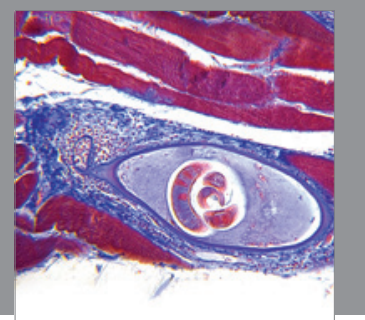

Gastroenterology

Research and Practice
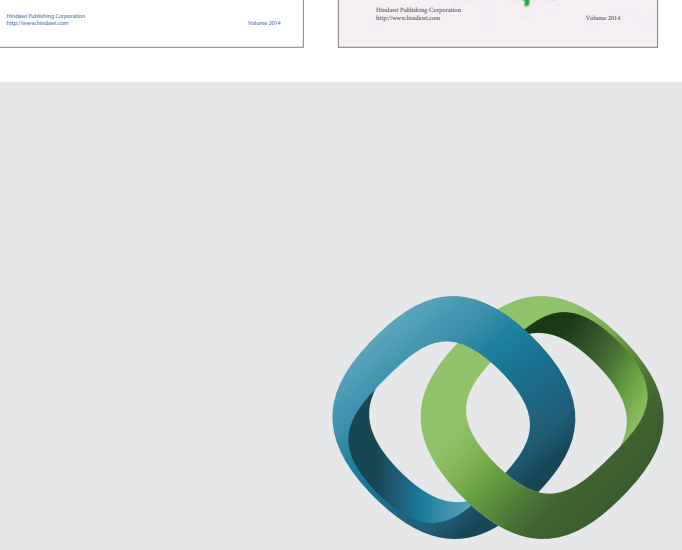

\section{Hindawi}

Submit your manuscripts at

http://www.hindawi.com
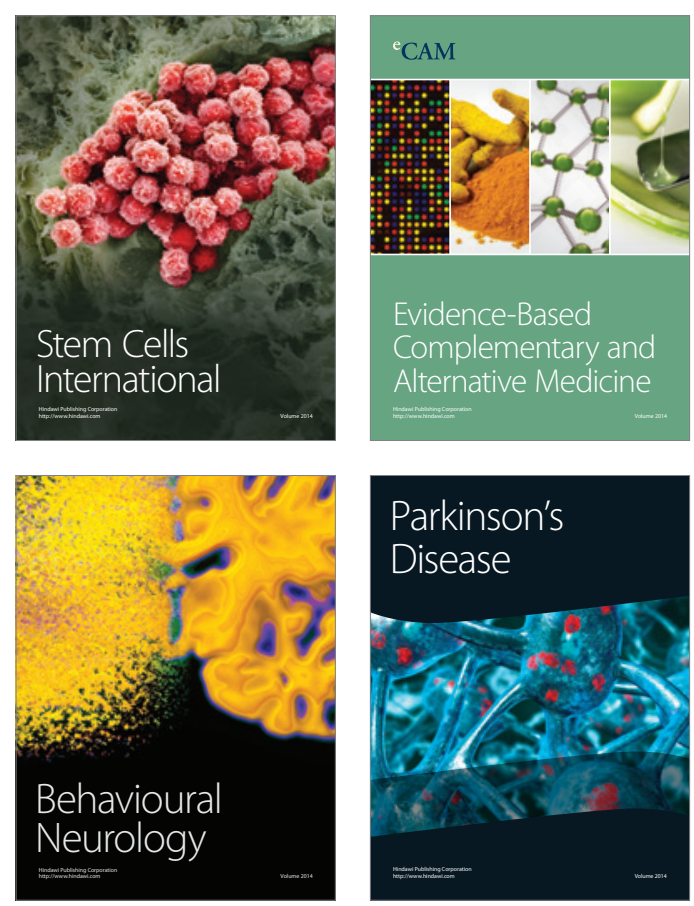

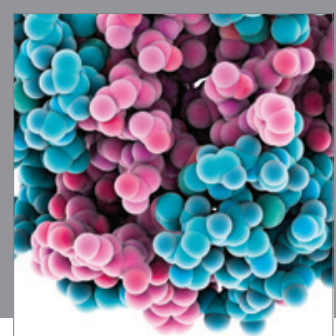

Journal of
Diabetes Research

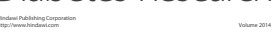

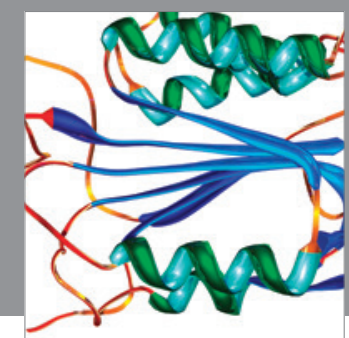

Disease Markers
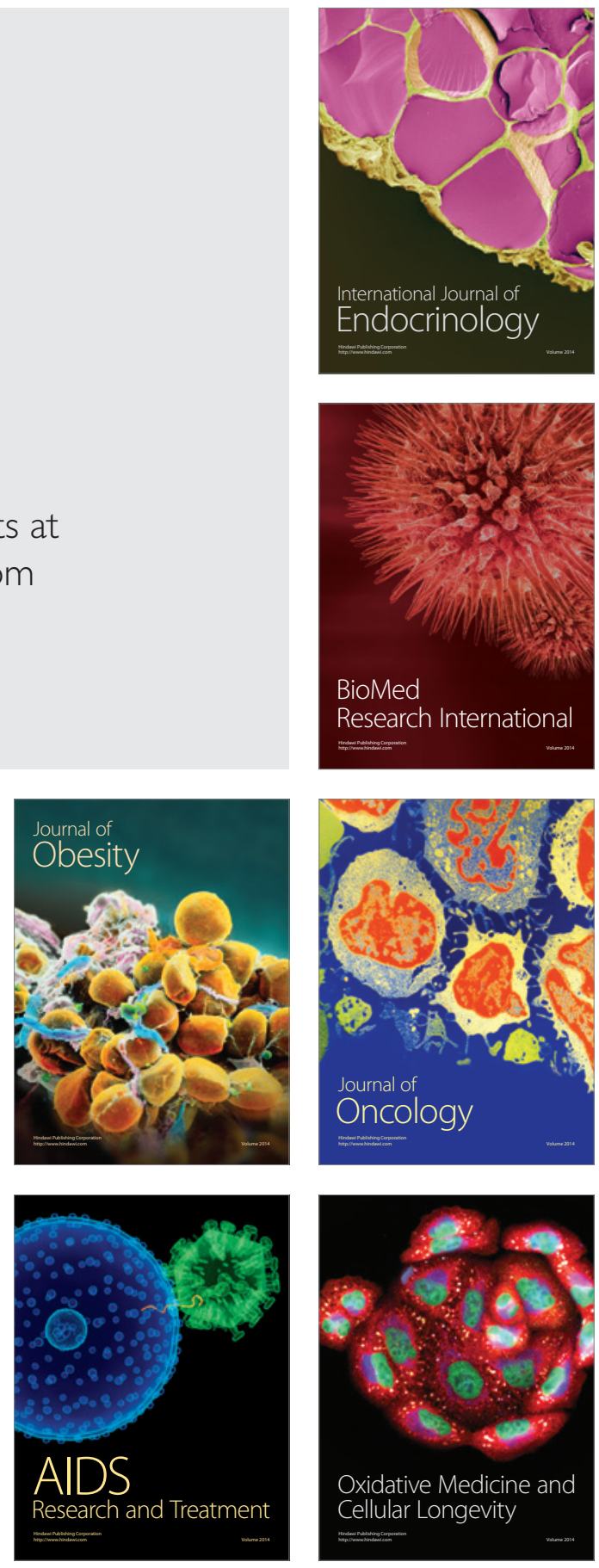